\title{
A Conceptual Rainfall-Runoff Model Using the Auto Calibrated NAM Models in the Sarisoo River
}

\author{
Maryam Hafezparast ${ }^{1 *}$, Shahab Araghinejad ${ }^{1}$, Sayed Ehsan Fatemi ${ }^{2}$ and Hanse Bressers ${ }^{3}$ \\ ${ }^{1}$ Department of Irrigation \& Reclamation Engineering, Faculty of Agricultural Engineering \& Technology, College of Agriculture \& Natural Resources, University of Tehran, \\ Karaj, Tehran, Iran \\ ${ }^{2}$ Department of Environmental Civil Engineering, Faculty of Civil Engineering, K.N.Toosi University of Technology, Tehran, Iran \\ ${ }^{3}$ Twente center for studies in Technology and Sustainable Development(CSTM), University of Twente, Enschede, The Netherland
}

\begin{abstract}
This paper describes the application of a conceptual rainfall runoff model to investigate the peak and monthly flows at the Sarisoo River Basin on the North West of Iran. The model was calibrated using measured stream flow data and then validated for three years.
\end{abstract}

Calculations of level and time of peak flows are vital for designing structures downstream in the catchment areas. The simulated peak flows were occurring in the months of February in 2003, 2006 and 2007 with approximate values of $6.32,9.35$ and $6.13 \mathrm{~m}^{3} \mathrm{~s}^{-1}$ respectively. After calibrating 9 NAM parameters using record data of daily rainfall, monthly evaporation and daily discharge in the period of $1^{\text {th }}$ October 2003 to $31^{\text {th }}$ March 2006 and validating the model daily discharges were calculated for 12 years.

The outputs of the calibrated model are able to be used in the assessment of water resources management models like Mike Basin, WEAP... because they normally work based on monthly flows with a large time horizon. The results show that monthly averages of mean, maximum and minimum flows are about $10 \%, 2 \%$ and $33 \%$ less than daily computed Nash-Sutcliffe coefficients, all calculated over a period of 12 years.

The optimum values of the 9 NAM parameters obtained during the calibration procedure are presented. The reliability of MIKE11 NAM was evaluated based on the Nash-Sutcliffe coefficient $\left(R^{2}\right)$, Root Mean Square Error (RMSE), peak flow (RMSE) and low flow (RMSE). The $\mathrm{R}^{2}$ obtained during this study is 0.74 .

Keywords: Rainfall-runoff models; Water balance; NAM parameters estimation; Calibration; Sarisoo River

\section{Introduction}

Appropriate river flow forecasting and estimation are the essential parameters to enable calculations of flood warning, drought forecasting and optimal operation of the reservoirs and power plants. There are a lot of approaches to hydrologic forecasting that have been used in the last few decades. These are grouped into three categories: lumped conceptual models, models based on physical distributions and empirical black box models. Lumped conceptual models require significant amounts of calibration data and also experience of the user to implement and calibrate. Physical distribution based models are not suitable for our research because they need a large amount of data about topology, soil, vegetation and geological characteristics of the catchment areas. The quality of the observed data plays the main role in the accuracy of empirical black box models and they are useful operational tools where there are not enough meteorological data available Babovic and Bojkow [1]. Precipitation distribution, evaporation, transpiration, abstraction, watershed topography, and soil types are implicit and explicit factors which are affecting the rainfallrunoff process in the modeling Dawson et al. [2].

The Rational Method McPherson [3], Soil Conservation ServiceCurve Number Method Maidment [4], and Green and Ampt Method Green and Ampt [5] are the widely known rainfall runoff models identified. The Genetic Danish MIKE11 NAM (1972) is one of the complex models identified which should provide better runoff estimation Supiah and Normala [6].

Lumped conceptual type of models have been developed based on conceptual representations of the physical processes of the water flow lumped over the entire catchment area. Examples of this type of model are the Sacramento model Burnash [7], the Tank model Sugawara [8], the HBV model Bergström [9], and the MIKE 11/ NAM model Nielsen and Hansen; Havnø et al. [10,11]. Model calibration is needed because the parameters of such models cannot be obtained directly from measurable quantities of catchment characteristics. A trial-and error parameter adjustment is made in the process of manual calibration. In this case, comparing the simulated and the observed hydrographs based on a visual judgment is used as a basis for the calibration process. In automatic calibration, parameters are automatically adjusted according to a specified search scheme and the resulting numerical measures of the goodness-of-fit Madsen [12].

MIKE 11-NAM is a rainfall-runoff model that is part of the MIKE 11 RR module. It has been used by many researchers [13-18]. MIKE 11-NAM, MIKE SHE and WATBAL models are validated on three catchments in Zimbabwe for water resources decision making by Refsgaard and Knudsen [13] where at least one year's data were available for calibration.

The runoff hydrographs for the ungauged Nzhelele River were simulated by using the MIKE 11-NAM model and the Australian

*Corresponding author: Maryam Hafezparast, Water Resources Engineering, University of Tehran, Iran, Tel: +989131270848; E-mail: hafezpst@ut.ac.ir

Received November 29, 2012; Accepted January 24, 2013; Published January 26, 2013

Citation: Hafezparast M, Araghinejad S, Fatemi SE (2013) A Conceptual RainfallRunoff Model Using the Auto Calibrated NAM Models in the Sarisoo River. Hydrol Current Res 4: 148. doi:10.4172/2157-7587.1000148

Copyright: @ 2013 Hafezparast M, et al. This is an open-access article distributed under the terms of the Creative Commons Attribution License, which permits unrestricted use, distribution, and reproduction in any medium, provided the original author and source are credited. 
Water Balance Model (AWBM) by Makungo et al. [18]. The simulated runoff hydrographs can be used in water resources planning and management, and water resources systems operation. The rainfallrunoff relationship in the Strymonas River catchment was studied by Doulgeris et al. [19] using the MIKE 11-NAM model. MIKE 11-NAM was used as well for the simulation of rainfall-runoff process in the Strymonas River and Lake Kerkini by Doulgeris et al. [20] for water resources management aspects.

Guzha and Hardy [21] used distributed models together with GISbased data, which enables subdividing the watershed into as small units as found necessary to utilize the available geospatial data. They applied the TOPNET model to the Big Darby Creek watershed in Ohio, USA. RVCA (2007a and Ahmed [22,23] used the Mike11 models for RVCA watersheds. It has recently been modified for smaller lake-dominated basins (as required by practical needs) and used for calculating design floods, stage-discharge rating curves, flood risk elevations, etc. (RVCA 2011a, b, 2012a, b) [24-27].

In this paper, using lumped conceptual rainfall-runoff models, a long term daily and monthly discharge (1996- 2008) has been calculated for the Sarisoo River catchment based on the available rainfall and evaporation data. For this purpose, the MIKE 11-NAM model was adopted in order to be able to do better auto calibration of Nam parameters. The calibration and validation procedures of the model were carried out to provide a satisfactory estimation. The subject matter of this paper is the application of a rainfall-runoff model for the Sarisoo River watershed on the northwestern part of Iran. Its location on the map of Iran is shown in Figure 1.

\section{Theory and Methodology}

The NAM (Nedbør Affstrømnings Model) model is a deterministic, lumped conceptual rainfall-runoff model which is originally developed by the Technical University of Denmark Nielsen and Hansen [10].

In this model, the hydrological cycle is the basis of the quantitative simulation of water storage and flows in the watershed and its parameters represent an average value for the whole watershed. The general structure of the model with its four different and mutually interrelated storages and their corresponding flows is shown in Figure 2.
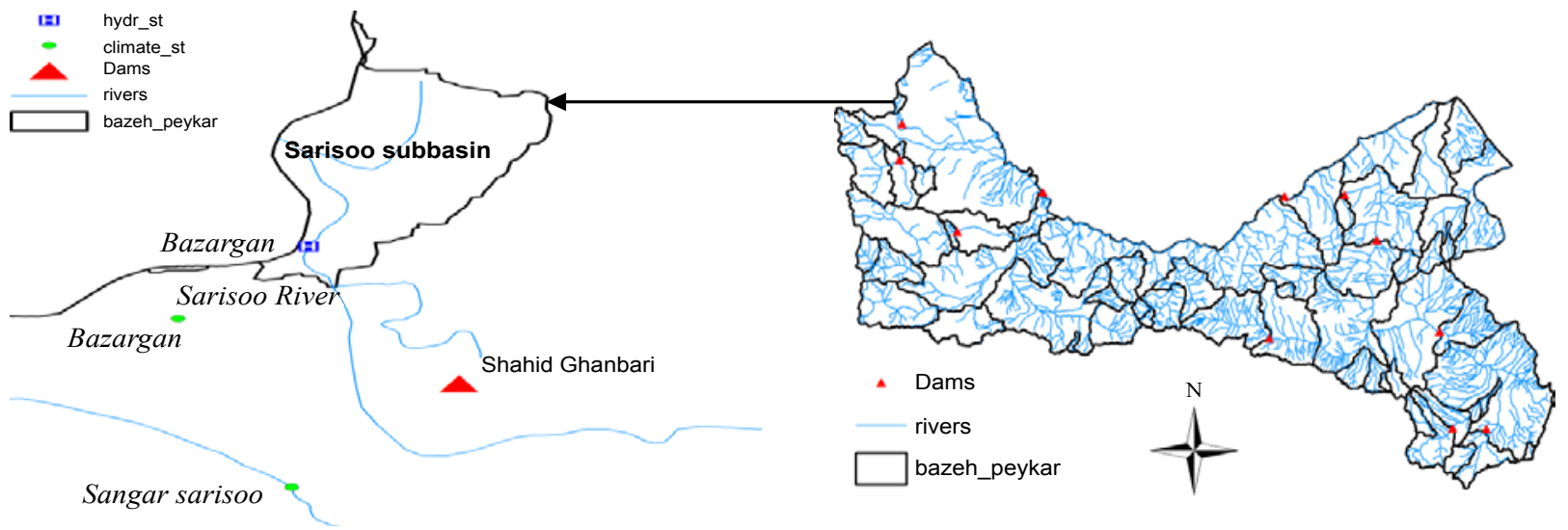

Figure 1: Aras River Basin and Sarisoo sub basin.
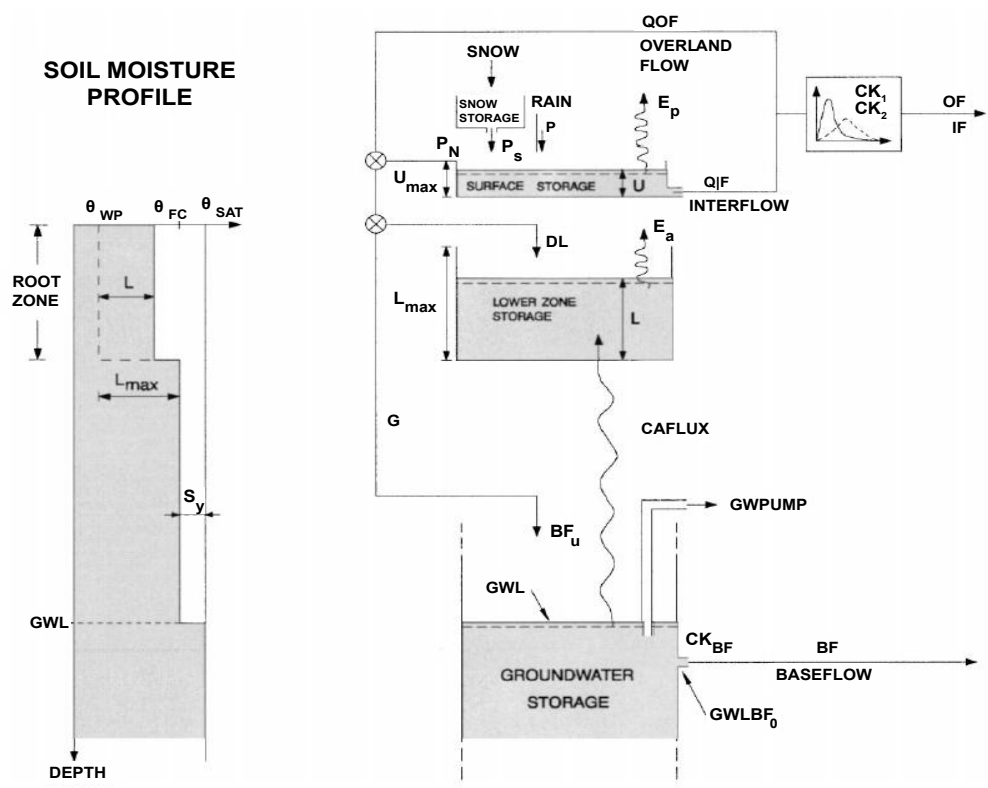

Figure 2: Nam model structure. 
The snow storage, surface storage, lower zone storage and underground storage are four storage layers and the flow (QOF), interflow (QIF) and underground flow $(\mathrm{QBF})$ are three flows surface. Generally, rainfall, potential evaporation and temperature are the input data needed for this model and the output of the model is the watershed outflow over time DHI [28].

To estimate the final NAM parameters the model must be calibrated by a time series of hydrological observations which can be done either manually or automatic. The auto-calibration is done to optimize two objective functions: (a) minimizing the water balance error (\%WBL) to achieve agreement between the average simulated and observed runoff; and (b) minimizing the overall Root Mean Square Error (RMSE) for the entire flow spectrum to achieve overall agreement of the shape of the hydrograph, by (Madsen 2000, 2003) [12,29].

The NAM auto calibration is implemented by giving all objectives equal weightage and by searching the solution by the shuffled complex evolution algorithm to avoid the optimum solution becoming entrapped in local optimums (Madsen 2000, 2003) [12,29].In this paper, the calibration scheme includes the overall volume error and the overall root mean square error (RMSE) performance statistics (Madsen, 2000; DHI, 2009) [12,28]. Calibration of the rainfall-runoff model (RR or NAM) is done by adjusting nine NAM parameters and by finding appropriate parameters for describing the initial conditions. Initially, the NAM model was setup using nine parameters (surfaceroot zone, groundwater). The catchments' parameters were estimated with a calibration procedure that was based on available discharge data. Two extended groundwater parameters (recharge to lower reservoirs and a time constant for routing lower base flow) in order to simulate a slower base flow in catchments were chosen to improve the model performance. The estimation of these parameters was achieved by the auto-calibration procedure.

Calibration of the NAM 11 RR model was then done for a two and a half year period from October 1st, 2003 through March 31 $1^{\text {st }}, 2006$, using measured flow data at Bazergan (19007) station.

The first stage of the application of the NAM model for rainfall runoff estimation is the calibration process to determine the optimum values of the model parameters. The second stage is the discharge simulation and the prediction based on the estimated model parameters during the calibration process.

\section{Data Sets}

The Sarisoo River watershed is located on the northwestern part of Iran and occupies a total area of $2470 \mathrm{~km}^{2}$. The available meteorological and hydrological parameters in the Sarisoo River catchment were analyzed and used in the calibration and validation of the hydrological model. Precipitation and temperature data were gathered from the Bazergan (19007) and Sangar-Sarisoo (19073) stations. The average annual precipitation is $335 \mathrm{~mm}$. Observed discharge measurements were obtained from the Bazergan station (19007) along the Sarisoo River and the mean annual discharge there is $1.35 \mathrm{~m}^{3} \mathrm{~s}^{-1}$ in a simulation for a period of 12 years. Hydrological (i.e., discharge) and meteorological (i.e., precipitation, temperature and potential evapotranspiration) data were input into the NAM model. In the NAM model, the actual evapotranspiration is calculated by the model and based on potential evapotranspiration (maximum rate of actual evapotranspiration) and on the model's parameters [28].

\section{Results and Discussion}

The MIKE 11-NAM model is used to estimate the daily runoff to the Sarisoo River catchment. The calibration period has been from $10 / 10 / 2003$ until $31 / 03 / 2006$ and the validation period from $01 / 09 / 2007$ until 29/02/2008. Following the auto-calibration procedure for the NAM model parameters, a set of NAM model parameters is calculated and then the simulated discharge is compared with observations.

By considering the structure of the NAM model, it seems that the final calculated values of model parameters represent hydrologically the catchment's characteristics in the range of predefined bandwidth during the auto-calibration procedure. The final values of NAM parameters that have been adjusted in the calibration process are illustrated in Table 1.

Figure 3 is showing a graphical evaluation of the MIKE 11-NAM model's results, for the 2003-2006 calibration periods and for the Bazergan station. It shows the result of auto-calibration yielded \%WBL and $\mathrm{R}^{2}$ values of $0.0 \%$ and 0.74 respectively.

The runoff peaks and the dates at which they appear are simulated with precision by the NAM model, in spite of the inability to simulate the higher peaks in some cases (April 2004 and 2005). However, in this paper we are mostly interested with significant precision in the runoff peaks and the dates and mean monthly runoff of the Sarisoo River. We are interested as well in the prediction of the daily and monthly discharges during the four years which are missed in historical time series of observed discharges, the years between 2000 to 2003 and 2006 2007.

Daily discharges were predicted for the period of $1^{\text {th }}$ September 2007 to $29^{\text {th }}$ February 2008 to validate the MIKE 11-NAM model using the model parameters estimated during the calibration period. A comparison between observed and simulated discharge for the validation period is illustrated in Figure 3.

\begin{tabular}{|c|c|c|c|c|}
\hline Parameters & Description & Upper Bound & Lower Bound & Final Value \\
\hline$U_{\max }(m m)$ & Maximum water content in surface storage ${ }^{*}$ & 5 & 35 & 5.01 \\
\hline $\mathrm{L}_{\max }(\mathrm{mm})$ & Maximum water content in root zone storage & 50 & 350 & 51.2 \\
\hline CQOF (-) & Overland flow runoff coefficient & 0 & 1 & 0.127 \\
\hline CKIF (hr) & Time constant for routing interflow & 500 & 1000 & 780.6 \\
\hline $\mathrm{CK} 1,2$ (hr) & Time constant for routing overland flow & 3 & 80 & 79.9 \\
\hline TOF (-) & Root zone threshold value for overland flow & 0 & 0.99 & 0.90 \\
\hline TIF (-) & Root zone threshold value for interflow & 0 & 0.99 & 0.00015 \\
\hline TG (-) & Root zone threshold value for GW recharge & 0 & 0.99 & 0.412 \\
\hline $\begin{array}{l}\text { CKBF (hr) } \\
\text { Cqlow (-) } \\
\text { Cklow (hr) }\end{array}$ & $\begin{array}{l}\text { Time constant for routing base flow Lower base flow/recharge to lower reservoir Time } \\
\text { constant for routing lower base flow }\end{array}$ & $\begin{array}{c}500 \\
0 \\
1000\end{array}$ & $\begin{array}{c}6000 \\
100 \\
30000\end{array}$ & $\begin{array}{c}5951 \\
62.7 \\
18108 \\
\end{array}$ \\
\hline
\end{tabular}

*See DHI [28] for details

Table 1: NAM parameters determined during calibration of Sarisoo catchment. 


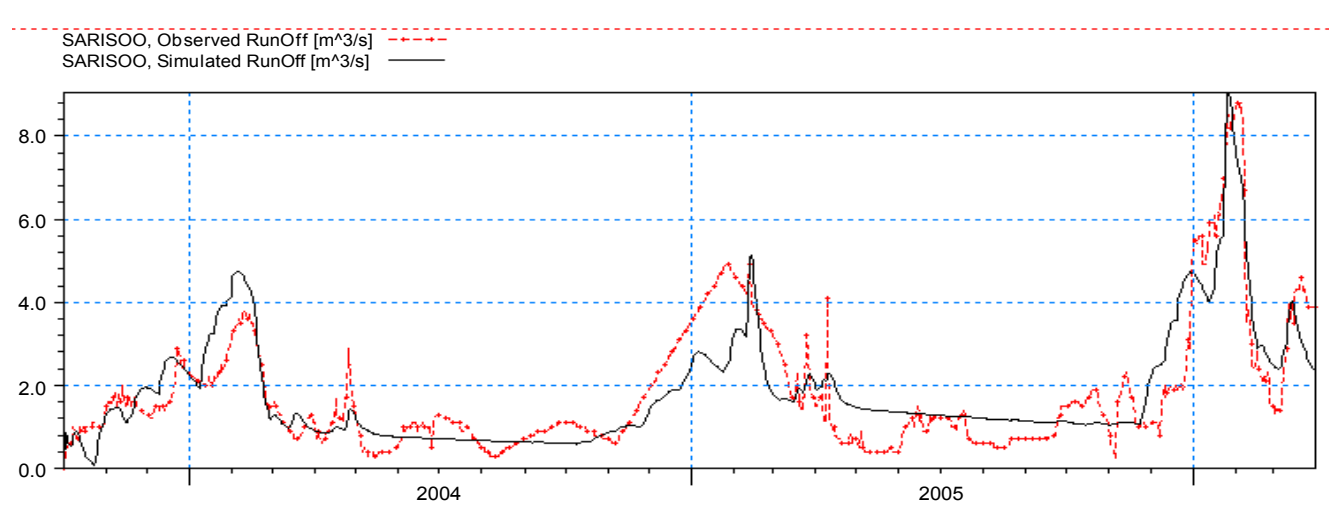

SARISOO, Accumulated Qobs. Million [ $\left[\mathrm{m}^{\wedge} 3\right]-\ldots-\cdots-$ SARISOO, Accumulated Qsim. Million $\left[\mathrm{m}^{\wedge} 3\right]$

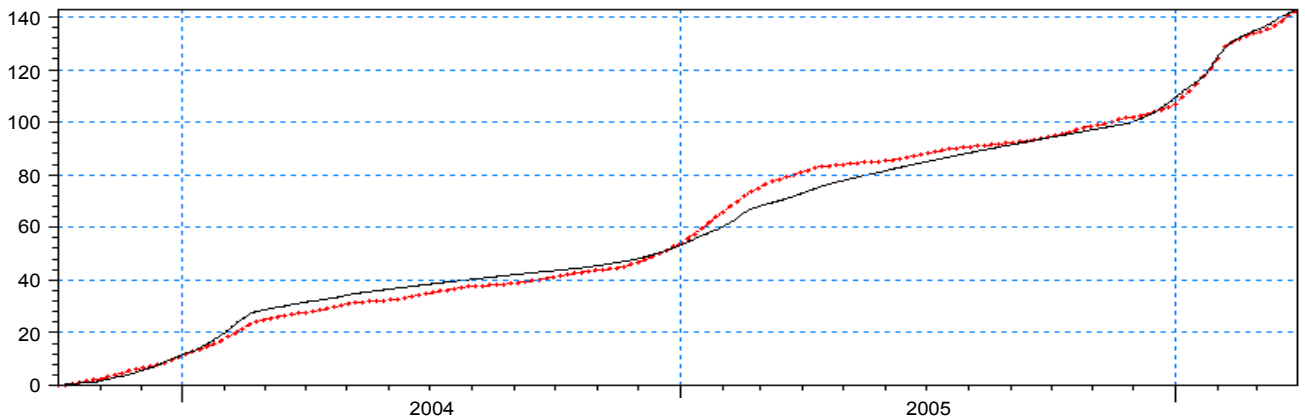

Figure 3: NAM Autocalibration at Bazargan station (19007).

The discharge series are simulated based on the daily rainfall and using parameters that were calculated during the calibration period for the 12-year period, 1996 to 2008. As there are four years of lacking data (Oct 2000 to Sep 2003 and Oct 2006 to Sep 2007) on the daily discharge of the Sarisoo watershed, it was important to know whether the peak flow could have been occurred in these periods. The results shown that the simulated peak flows were occurring in the February months of 2003, 2006 and 2007 with approximate values of 6.32, 9.35 and 6.13 $\mathrm{m}^{3} \mathrm{~s}^{-1}$ respectively. It means that the peak flow will not be occurring in the data gap periods between 1996 to 2008. Simulated daily discharge data were compared with the observed daily flows that validated the peak flow dates and values. The peak of the observed daily discharge was measured $8.8 \mathrm{~m}^{3} \mathrm{~s}^{-1}$ in February 2006. The average, minimum and maximum discharges in the gap years were calculated to be $0.99,0.11$ and $6.32 \mathrm{~m}^{3} \mathrm{~s}^{-1}$ and 2.52, 1.73 and $6.14 \mathrm{~m}^{3} \mathrm{~s}^{-1}$ for the period of Oct 2000 to Sep 2003 and Oct 2006 to Sep 2007, respectively.

Furthermore, for the assessment of water resources management aspects, the monthly mean, minimum and maximum discharges were calculated based on the simulated daily discharge for the 1996-2008 years. Figure 4 represents the curves of the simulated and observed monthly mean minimum, maximum discharges. As seen in Figure 5 , the Nash-Sutcliffe coefficient $\left(\mathrm{R}^{2}\right)$ is calculated to be $62 \%, 72 \%$ and $40 \%$ for the monthly mean, minimum and maximum discharges respectively.

By comparing the output of the Nam model for calculating the daily discharge correlation coefficient $\left(\mathrm{R}^{2}=0.74\right)$ in the calibration of these values, it seems that there is a significant agreement between daily and monthly maximum discharges $\left(\mathrm{R}^{2}=0.72\right)$ and the observed discharges. And also there is an acceptable agreement between daily and monthly average discharges $\left(\mathrm{R}^{2}=0.62\right)$ and the observed discharges but there is an insignificant agreement between daily and monthly average discharge $\left(\mathrm{R}^{2}=0.40\right)$ against of observed discharge. However, monthly averages of mean, minimum and maximum flows are about $10 \%, 33 \%$ and $2 \%$ respectively less than the daily computed Nash-Sutcliffe coefficients over the period of the 12 years. It means that in this case study using the results of the Nam model to calculate the daily discharge of the watershed from daily rainfall it is acceptable to use monthly discharges in water management models like the Mike basin, WEAP, ... in middle term time series. Because monthly averages and maximum discharges are more important than monthly minimum discharge to calculate the designs of downstream infrastructures and the reservoirs in the basin can moderate and manage the minimum flows. Figure 5 demonstrates the simulated monthly runoff of the Sarisoo watershed.

The probabilities of exceeding the curves of monthly average flows for simulated and observed discharges are shown in Figure 6. This graph shows that there are three periods of time to compare the model results with. At first there is a very good correlation between observed and simulated data for monthly maximum discharges (the first initial $20 \%$ of the time). And also, it shows that the simulated discharge is overestimated and underestimated by the model for monthly average and minimum flows respectively in the second part (the next $40 \%$ of the time) and third part (the last $40 \%$ of the time) Figure 7.

\section{Conclusions}

The estimation of rainfall runoff in a watershed is very important when these values are required for the purpose of water resources planning. Monthly and peak flows are the two most important criteria to design the reservoirs and for water basin management planning.

The rainfall-runoff model (MIKE 11-NAM) was applied to the Sarisoo catchment for a twelve-year time period. We have been 
using an automatic calibration to calculate and calibrate the model's parameters against the observed discharges along the Sarisoo River over a period of two and half consecutive years. The model's results were significantly improved by the use of additional groundwater parameters. Furthermore, the model was also validated for the period 01/09/2007 to 29/02/2008 and satisfactorily predicted the Sarisoo River discharges.

In this paper there are two issues most interesting to estimate with

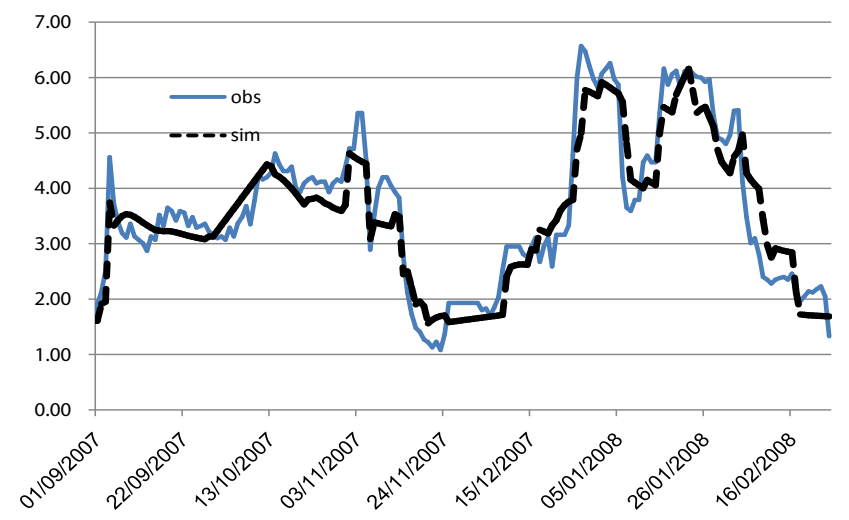

Figure 4: Validation graph
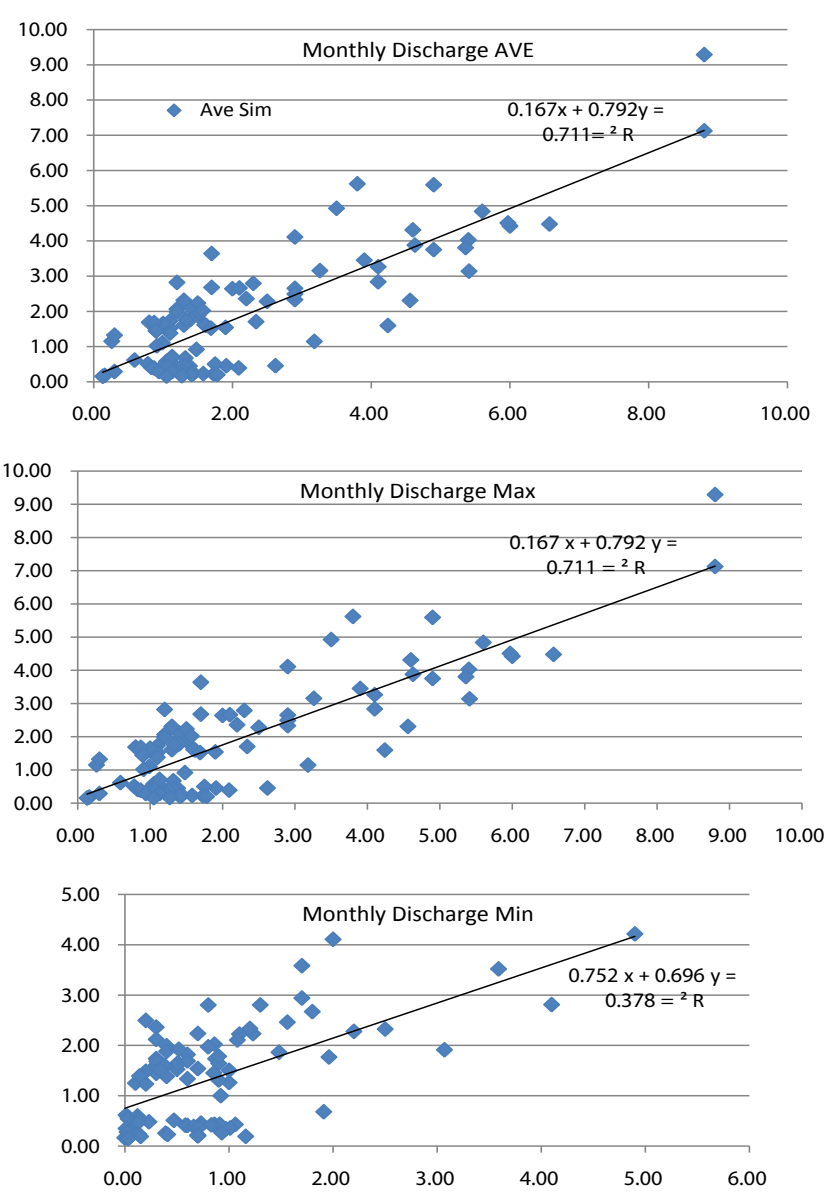

Figure 5: The curves of simulated and observed monthly mean, minimum, maximum discharges.

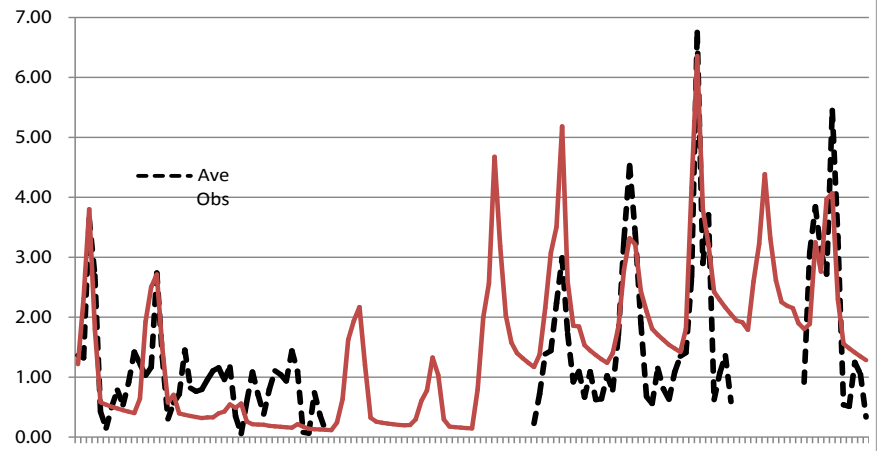

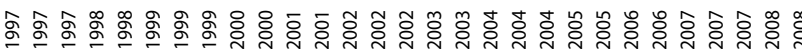

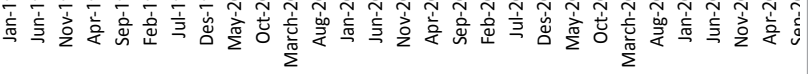

Figure 6: The simulated monthly runoff of the Sarisoo watershed.

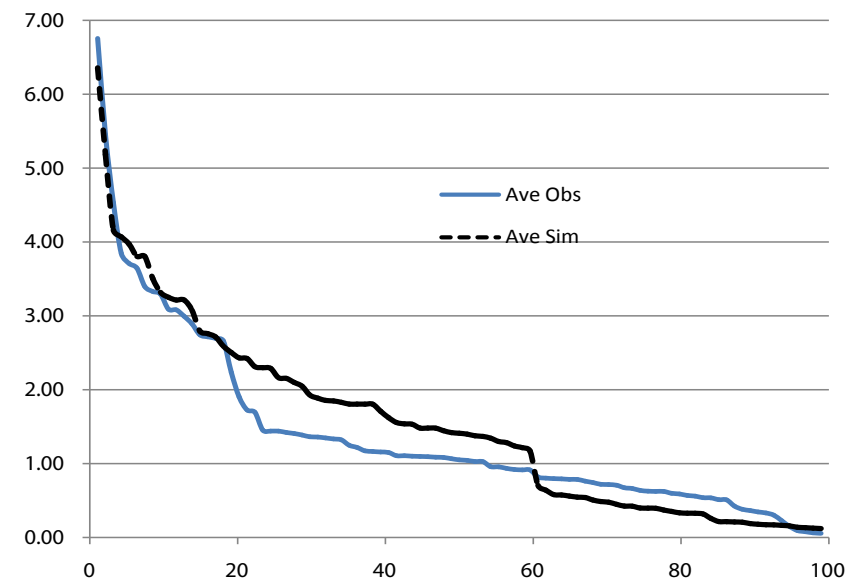

Figure 7: The exceedance probability curve of monthly average flows for simulated and observed discharge.

significant precision: the discharge of the Sarisoo River including the runoff peaks and their dates and the mean monthly runoff. Prediction of daily and monthly discharges for the four years which are missed in the historical time series of observed discharge between 2000 to 2003 and 2006-2007 years is interesting as well. The results show that the simulated peak flows were occurring in the February months of 2003, 2006 and 2007 with approximate values of $6.32,9.35$ and $6.13 \mathrm{~m}^{3} \mathrm{~s}^{-1}$ respectively. Average, minimum and maximum discharges in gap years are calculated to be $0.99,0.11$ and $6.32 \mathrm{~m}^{3} \mathrm{~s}^{-1}$ and $2.52,1.73$ and 6.14 $\mathrm{m}^{3} \mathrm{~s}^{-1}$ for the periods of Oct 2000 to Sep 2003 and Oct 2006 to Sep 2007, respectively.

The monthly discharges including mean, minimum and maximum flows were calculated based on the simulated daily discharges for the 1996-2008 years to assess water resources management aspects. When comparing the output of the Nam model for the calculated daily discharges with observed data that was a significant correlation found $\left(\mathrm{R}^{2}=0.74\right)$ in the calibration stage. However the monthly averages of mean, minimum and maximum flows are about $10 \%, 33 \%$ and $2 \%$ respectively less than the daily computed Nash-Sutcliffe coefficients in the 12 years period.

Monthly averages and maximum discharges are more important than monthly minimum discharges to calculate the designs of 
downstream structures while the reservoirs in the sub basins can moderate and manage the minimum flows. Therefore, in this case study using the results of the Nam model for the calculation of the daily discharges from rainfall of the watershed it is acceptable to use the monthly discharges in water management models like Mike basin, WEAP, ... in middle term time series. The rainfall-runoff models like especially MIKE 11-NAM are lumped conceptual type of models and they don't need a lot of data to calculate daily and then monthly discharges. So, they are useful tools to use in water management models on the large scale modeling with middle and long term simulation periods. Finally, the pack of Mike Basin model including Mike Nam, 11 and Basin is a modeling system that they will satisfy the requirements of water resources managers.

\section{Acknowledgment}

This paper was made possible after help from the East, West Azerbaijan and Ardebil Regional Water Company and also the Mahab Ghodss Consulting Engineering Company by providing the basic simulation data. This work was also funded by Helps of DHI Company for getting the license for the Mike models.

\section{References}

1. Bojkow VH (2001) Runoff Modelling with Genetic Programming and Artificial Neural Networks. D2K Technical Report D2K TR 0401-1.

2. Dawson CW, Brown MR, Wilby RL (2000) Inductive learning approaches to rainfall-runoff modelling, Int J Neural Syst 10: 43-57.

3. McPherson MB (1969) Some notes on the Rational Method of Storm Drain Design, Tech. Memo. ASCE, Water Resources Research Program. Harvard University, Cambridge, USA.

4. Maidment DR (1993) Handbook of Hydrology, (1stedn). NewYork, McGraw Hill: 1424.

5. Green WH, Ampt GA (1911) Studies on soil physics. Journal of Agricultural Sciences 4: 1-24.

6. Supiah S, Normala H (2002) Rainfall Runoff simulation using Mike11 nam. Journal of civil engineering 15: 26-38.

7. Burnash RJC (1995) The NWS River forecast system-- catchment modeling In: Singh VP, (eds.). Computer Models of Watershed Hydrology, Water Resources Publications, Colorado 311-366.

8. Sugawara M (1995) Tank model In: Singh VP, (eds.). Computer Models of Watershed Hydrology, Water Resources Publications, Colorado: 165-214.

9. Bergstrom S (1995) The HBV model In: Singh VP (eds.). Computer Models of Watershed Hydrology, Water Resources Publications, Colorado: 443-476.

10. Nielsen SA, Hansen E (1973) Numerical simulation of the rainfall-runoff process on a daily basis. Nordic Hydrol 3: 171-190.

11. Havnø K, Madsen MN, Dørge J (1995) MIKE 11 - a generalized river modelling package In: Singh VP (eds.). Computer Models of Watershed Hydrology, Water Resources Publications, Colorado: 733-782.

12. Madsen H (2000) Automatic calibration of a conceptual rainfall-runoff mode using multiple objectives. Journal of Hydrology 235: 276-288.

13. Refsgaard JC, Knudsen J (1996) Operational Validation and Intercomparison of Different Types of Hydrological Models. Water Resources Research 32: 2189-2202.
14. Thompson JR, Sørenson HR, Gavin H, Refsgaard A (2004) Application of the coupled MIKE SHE/MIKE 11 modelling system to a lowland wet grassland in southeast England. Journal of Hydrology 293: 151-179.

15. Keskin F, Şensoy AA, Şorman A (2007) Application of MIKE11 Model for the Simulation of Snowmelt Runoff in Yuvacik Dam Basin, Turkey. International Congress on River Basin Management, The role of general directorate of state Hydraulic works (DSI) in development of water resources of Turkey.

16. Liu HL, Chen X, Bao AM, Ling Wang (2007) Investigation of groundwater response to overland flow and topography using a coupled MIKE SHE/MIKE 11 modeling system for an arid watershed. Journal of Hydrology 347: 448-459.

17. Kamel AH (2008) Application of a hydrodynamic MIKE 11 model for the Euphrates River in Iraq. Slovak Journal of Civil Engineering 2: 1-7.

18. Makungo R, Odiyo JO, Ndiritu, Mwaka (2010) Rainfall-runoff modelling approach for ungauged catchments: A case study of Nzhelele River subquaternary catchment. Physics and Chemistry of the Earth 35: 596-607.

19. Doulgeris C, Halkidis I, Papadimos D (2008) Use of Modern Technology for the Protection and Management of Water Resources in Strymonas/Struma River Basin, Technical Report, Greek Biotope/Wetland Centre (EKBY) Therm Greece: 82.

20. Doulgeris C, Georgiou P, Papadimos D, Papamichail D (2012) Ecosystem approach to water resources management using the MIKE 11 modeling system in the Strymonas River and Lake Kerkini. J Environ Manage 94: 132-143.

21. Guzha AC, Hardy TB (2010) Application of the Distributed Hydrological Model TOPNET, to the Big Darby Creek Watershed, Ohio, USA. Water Resour Manage 24: 979-1003.

22. RVCA (2007) Rideau River Watershed modeling using Mike11, Draft Report Rideau Valley Conservation Authority, Manotick, Canada.

23. Ahmed F (2010) Numerical modeling of the Rideau Valley Watershed. Nat Hazard 55: 63-84.

24. RVCA (2011a) Analysis of regulatory flood level on the shoreline of Otter Lake for the purposes of administering Ontario Regulation 174/06, Rideau Valley Conservation Authority, Manotick, Canada.

25. RVCA (2011b) Analysis of regulatory flood level on the Shoreline of Otty Lake for the purposes of administering Ontario Regulation 174/06, Rideau Valley Conservation Authority, Manotick, Canada.

26. RVCA (2012a) Analysis of regulatory flood level on the shoreline of Bobs Lake for the purposes of administering Ontario Regulation 174/06, Rideau Valley Conservation Authority, Manotick, Canada.

27. RVCA (2012b) Analysis of regulatory flood level on the shoreline of lower/big Rideau Lake, for the purposes of administering Ontario Regulation 174/06, Rideau Valley Conservation Authority, Manotick, Canada.

28. DHI (2009) MIKE 11: A Modeling System for Rivers and Channels, Reference Manual, Danish Hydraulic Institute, Denmark.

29. Madsen H (2003) Parameter estimation in distributed hydrological catchment modelling using automatic calibration with multiple objectives. Adv Water Resour 26: 205-216. 